\title{
POLÍTICA EXTERNA EM PERSPECTIVA: UM BALANÇO SOBRE A DIPLOMACIA DOS PRESIDENTES COLLOR, ITAMAR, CARDOSO E LULA
}

\section{Introdução}

Carlos Ribeiro Santana ${ }^{1}$

Um traço da diplomacia brasileira é a capacidade de expandir e diversificar as relações internacionais do Brasil. Considerando-se as dimensões do País, a necessidade de uma presença universal mostra-se natural e indispensável. A flexibilidade da ação externa - no sentido de não haver focos únicos, excludentes - expande a agenda diplomática tanto temática quanto geograficamente. Dessa forma, o acervo de participação positiva da diplomacia brasileira, sempre apoiada em critérios de legitimidade, amplia o leque de atuação da política externa frente aos rumos da ordem internacional.

O presente artigo busca estudar a política externa do Brasil, os seus condicionantes internos e externos e as relações bilaterais e multilaterais do País no contexto dos últimos quatro Presidentes, levando-se em conta características conceituais e práticas. Convém ressaltar que a política externa envolve aspectos mais determinados dentro do conjunto das relações internacionais, enfocando a "orientação governamental" de determinado Estado a propósito de determinados Governos e/ou Estados, ou ainda regiões, situações e estruturas em conjunturas específicas. Envolve os acervos diplomáticos permanentes, percebidos como fatores de continuidade e permanência. Orienta-se no sentido da consecução dos interesses nacionais no plano internacional. A política internacional, por sua vez, emerge da relação conflitiva ou interativa das políticas externas que compõem o sistema internacional. Refere-se a normas de conduta no âmbito mundial ou à política frente ao mundo contemporâneo. O artigo envolve, destarte, a política externa no sentido expresso acima.

\section{Resumo}

Um traço da diplomacia brasileira é a capacidade de expandir e diversificar as relações internacionais do Brasil. Durante as duas últimas décadas, o País teve quatro Presidentes que marcaram, cada um ao seu estilo, o encaminhamento da política externa. O presente artigo busca estudar a política externa do Brasil, os seus condicionantes internos e externos e as relações bilaterais e multilaterais do País no contexto dos últimos quatro Presidentes.

Palavras-chave: Política externa; Diplomacia; Brasil;

\begin{abstract}
:
A key characteristic of Brazilian diplomacy is its capacity to expand and diversify the country's international relations. During the last two decades Brazil has had four presidents who led foreign policy according to their individual styles. This article aims to study in both practical and conceptual terms Brazilian foreign policy, its domestic and international constraints, and the country's bilateral and multilateral relations during the last four presidencies.
\end{abstract}

\footnotetext{
${ }^{1}$ Diplomata e mestre em Relações Internacionais pela Universidade de Brasília. O presente artigo reflete apenas as opiniões pessoais do autor e não busca representar as posições oficiais do governo brasileiro.
} 
Keywords: Foreign policy, diplomacy, and Brazil

\section{O Governo Collor}

O Governo Collor, que assumiu em 1990, foi marcado por estilo personalista e imediatista, provocando a marginalização de certos quadros da burocracia estatal. De acordo com o Embaixador Paulo Nogueira Batista ${ }^{2}$, o ponto de partida da política externa do período foi "a intenção declarada de reexaminar os pressupostos do modelo de desenvolvimento brasileiro e da política externa que lhe dava apoio". Nesse sentido, a diplomacia deveria buscar a inserção competitiva do País na economia mundial frente ao contexto da filosofia neoliberal do chamado Consenso de Washington ${ }^{3}$. Para o Embaixador, durante a administração Collor, marcada pela diplomacia presidencial ${ }^{4}$, o Itamaraty não foi o principal formulador da política externa e nem participou ativamente de sua execução. Com efeito, o papel do Ministério das Relações Exteriores como formulador de quadros conceituais de política externa foi ligeiramente diminuído pelo presidencialismo personalista de Collor.

A inflexão da iniciativa presidencial como determinante da política externa ocorreu ao final de 1991, com a reforma ministerial que levou à nomeação de Celso Lafer para o Itamaraty, em substituição a Rezek. O novo Chanceler estaria mais em sintonia com o quadro diplomático do Ministério, embora traçasse críticas ao estilo do Itamaraty. Dessa forma, a gestão Lafer buscou compatibilizar as agendas interna e internacional com uma "combinação de tradição e inovação" na política externa. Um dos objetivos principais da diplomacia consistiu em reintegrar o País aos fluxos dinâmicos da economia mundial, no intuito de promover a inserção competitiva do Brasil.

As diretrizes da política externa do Ministro Lafer envolveram, basicamente, quatro elementos conceituais: as parcerias operacionais, os nichos de oportunidade, a adaptação criativa e a visão de futuro. ${ }^{6}$ As "parcerias operacionais" apresentavam-se no contexto da inserção competitiva do País, um dos objetivos fundamentais da política externa do Chanceler. Seriam predominantemente econômicas; porém, em alguns casos, com conteúdo político. Logo, o Mercosul era tido como a principal prioridade, seguido pelo relacionamento com a tríade:

\footnotetext{
${ }^{2}$ BATISTA, Paulo Nogueira. “A política externa de Collor: modernização ou retrocesso?”. Política Externa, vol. 1, n. 4, março de 1999, p. 108 e 122.

${ }^{3}$ Modelo de organização econômica que os representantes das agências governamentais dos Estados Unidos e de instituições internacionais de crédito, sediadas na capital estadunidense, haviam identificado como o mais adequado para a América Latina. O "Consenso" defende a submissão das economias latino-americanas às forças de mercado por meio de um Estado-mínimo, isto é, um Estado completamente ausente no plano micro-econômico e severamente limitado no plano macro-econômico, com atuação, basicamente, de regulador das transações econômicas internas e externas.

${ }^{4}$ A diplomacia presidencial não se resume à diplomacia das visitas e dos encontros. Segundo Sérgio Danese, é um imperativo inescapável para os Presidentes brasileiros, que não podem exercê-la apenas em suas atribuições básicas. Além disso, possui uma forte componente de política interna, que não pode ser ignorada pela Chancelaria. Por fim, constitui instrumento valioso, mas complexo, de política interna e externa, o qual, todavia, não pode ser usado indiscriminadamente em uma ou outra áreas. Cf. DANESE, Sérgio. Diplomacia Presidencial. Rio de Janeiro: Topbooks Editora, 1999, p. 50.

${ }^{5}$ Retirado do discurso de posse do Chanceler Lafer, em 13 de abril de 1992. In BRASIL/MRE. A inserção internacional do Brasil: a gestão do Ministro Celso Lafer no Itamaraty. Brasília, MRE, 1993, p. 33-34.

${ }^{6}$ Palestra do Ministro de Estado da Escola Superior de Guerra. Idem.
} 
Estados Unidos, União Européia e Japão. A política de parcerias operacionais visava a inserir o Brasil no sistema globalizado, auferindo ganhos com a liberalização multilateral do comércio, e a aproximá-lo dos países do centro da economia mundial.

Além de buscar parceiros operacionais, a política externa deveria explorar "nichos de oportunidades" que se apresentavam com o fim da Guerra Fria nos campos econômico e político. Em palestra na Escola Superior de Guerra, o Chanceler chamava a atenção para o potencial do relacionamento econômico bilateral com países como Irã, Turquia, Emirados Árabes Unidos, República da Coréia e Israel. Essa política coadunava-se com o objetivo da diplomacia de cultivar o multilateralismo "com nichos de tratamento diferenciado", como dizia o Ministro Lafer, buscando as oportunidades econômicas nas diversas frentes do relacionamento externo.

O Chanceler também cunhou dois conceitos para a nova diplomacia sob sua gestão: "adaptação criativa", que consistia em nova postura da política externa frente à realidade internacional da época; e "visão de futuro", que buscava a constituição de sistema internacional em consonância com os valores e as aspirações nacionais. No contexto desses novos conceitos e tendo como marco a Conferência das Nações Unidas sobre Meio Ambiente e Desenvolvimento (Conferência do Rio), em 1992, foi reforçada a ênfase conferida ao termo "desenvolvimento sustentável", derrubando barreiras impostas por questões ecológicas ao objetivo nacional do desenvolvimento. A partir da Conferência do Rio, o Itamaraty retomou o papel de coordenação no processo decisório da política externa, atenuado durante o início do Governo Collor.

A adaptação criativa consistia na ação de traduzir as necessidades internas em possibilidades externas. Dois exemplos, segundo o Chanceler, seriam a Conferência do Rio e a atitude do País diante dos regimes de controle de transferência de tecnologia sensível. ${ }^{7}$ De acordo com essa diretriz, o Brasil não deveria aceitar "imobilismos no mundo em constante transformação", bem como práticas e tendências que lhe eram desfavoráveis. A diplomacia deveria guiar-se pela combinação entre a tradição e a inovação, dosando sempre a ação pragmática com o idealismo.

A visão de futuro, por sua vez, seria a política externa "inspirada por aquele mínimo de utopia sem o qual o peso dos fatos e dos condicionamentos não será superado". Por meio desse elemento, o País reforçaria as estruturas de cooperação em matéria de comércio, investimento e transferência de tecnologia. Como exemplos de visão de futuro, pode-se citar a Agenda 21, aprovada durante a Conferência do Rio, a qual incorporou esse conceito "ao consolidar um programa de princípios de cooperação capazes de alterar a dinâmica simplista das relações de custo-benefício"; e a posição do Brasil favorável ao debate sobre a reformulação da composição do Conselho de Segurança das Nações Unidas.

A atuação do Ministro Lafer foi marcada pela Conferência do Rio e pela grande crise política interna, a qual culminou no afastamento do Presidente Collor. Nesse contexto, o Chanceler conferiu ênfase à Rio 92 como o ponto inaugural de nova era na diplomacia brasileira, cujas propostas de âmbito multilateral teriam tal peso que deveriam ser obrigatoriamente

\footnotetext{
${ }^{7}$ Nesse contexto, a Chancelaria mostrava-se disposta a "aceitar procedimentos eqüitativos de controle em troca de acesso a tecnologias". A postura diplomática balizava-se pela construção da confiança e da verificação, de um lado, e pelo direito à participação nos fluxos internacionais de alta tecnologia, do outro. Cf. LAFER, Celso. "A inserção internacional do Brasil". O Estado de São Paulo. Caderno "Espaço Aberto", 23 de maio de 1992.
} 
discutidas pelos países desenvolvidos. A Conferência do Rio teve também o papel de posicionar o Brasil como país mediador ou, como prefere Lafer, "construtor de consensos", haja vista a estratégia de aproximação com o mundo desenvolvido sem abrir mão da autonomia decisória nacional.

Por fim, a política externa do Governo Collor procurou, basicamente, instrumentalizar, em âmbito externo, o processo de reforma e de abertura econômica e restabelecer a credibilidade do País ante seus principais interlocutores no mundo industrializado. Buscou utilizar a política externa como ferramenta para ampliar a competitividade internacional do País, melhorando as condições de acesso a mercado, crédito e tecnologia. Todavia, a tentativa do Governo de abandonar o modelo estatista por meio de rápida implementação de políticas liberalizantes viu-se constrangida pela crise política deflagrada no primeiro ano do mandato presidencial. Do amplo pacote de reformas econômicas, envolvendo abertura comercial, liberalização de investimentos, privatização de empresas estatais e renegociação da dívida externa, manteve-se em marcha apenas as novas determinações no campo do comércio exterior. A atualização da agenda diplomática frente às mudanças ocorridas no cenário internacional também concorreu com a construção de agenda positiva com os Estados Unidos.

\section{O Governo Itamar}

O Governo Itamar foi igualmente curto como o do ex-Presidente Collor. Pode-se dizer que constituiu verdadeiro hiato na seara política nacional, uma vez que não produziu rupturas e nem, tampouco, a propositura de mudanças que despertassem de maneira intensa o debate político na sociedade. Todavia, a gestão Itamar cumpriu bem o papel de completar o mandato de seu antecessor, bem como de garantir a atmosfera política saudável para a continuidade do processo democrático iniciado em 1989, com a primeira eleição direta de um mandatário por sufrágio universal, após anos de regime militar.

No plano internacional, a atuação do Governo Itamar foi caracterizada pela adoção de posicionamento marcado pela condição do Brasil como país em desenvolvimento. Além disso, ao assumir a Presidência da República, Itamar Franco teve de lidar com a imagem deteriorada do Estado no plano externo, devido à desconfiança quanto às origens nacionalistas do Presidente e ao temor no tocante à não-continuidade das reformas iniciadas na gestão Collor. Como coloca Muller $^{8}$, o Presidente Itamar "era tido como caso desviante na América Latina, uma vez que o Brasil era o país mais atrasado na região com relação à estabilidade monetária e às reformas econômicas".

A ação diplomática refletia projeto de inserção internacional baseado, no plano conceitual, no Brasil como um "país baleia"9, com interesses múltiplos na dinâmica de globalização da economia mundial. De acordo com o Itamaraty ${ }^{10}$, os objetivos da política externa deveriam girar em torno das seguintes metas: defesa do multilateralismo como a melhor maneira

\footnotetext{
${ }^{8}$ MÜLLER, June Beatriz. A política externa brasileira nos governos Sarney, Collor e Itamar: um novo paradigma? Dissertação de Mestrado, Brasília: Universidade de Brasília, 2003, p. 130.

${ }^{9}$ Países em desenvolvimento com grande extensão territorial, com grandes populações e com economias pujantes. É o caso de Índia, China, Brasil e Rússia.

${ }^{10}$ BRASIL/MRE. Reflexões sobre a política externa brasileira. Brasília: FUNAG/IPRI, 1993 e BRASIL/MRE. A Política Externa do Governo Itamar Franco. Brasília: MRE, FUNAG, 1994.
} 
para tratar dos grandes temas políticos e econômicos contemporâneos e da maior democratização do processo decisório internacional; apoio à reforma das Nações Unidas, das instituições de Bretton Woods e do GATT; participação ativa nos debates a respeito de questões globais como meio ambiente, direitos humanos e desarmamento; participação nas variadas coalizões tanto globais quanto específicas como, por exemplo, o G-77, o Grupo do Rio e o Grupo de Cairns.

O Governo Itamar também buscou alçar o Brasil à condição de ator protagônico no processo de regionalização em curso no âmbito hemisférico. Com relação a iniciativas nesse sentido, pôde-se observar o reforço da prioridade das relações com a América Latina, mormente com a América do Sul - englobando as dimensões política, social e econômica, mas sem descuidar da dimensão de segurança, isto é, das questões de narcotráfico e terrorismo. No período, o Presidente sugeriu inclusive que fosse criada, em contrapartida à pretendida Área de Livre Comércio das Américas (Alca), a Área de Livre Comércio Sul-Americana (Alcsa). Observou-se também a busca por melhores relações com os Estados Unidos, com a Comunidade Européia, com o Japão e a ampliação dos vínculos diplomáticos com China, Rússia e Índia.

Todavia, foi nos foros multilaterais onde melhor se pode perceber a atuação da diplomacia no sentido de imprimir maior visibilidade ao País frente à comunidade internacional. Assim, o Itamaraty buscou assegurar voz e voto para o Brasil no processo de reforma institucional da ordem internacional. Grande destaque foi concedido à defesa do sistema econômico multilateral, ao reforço do relacionamento com cada um dos três grandes espaços econômicos (NAFTA, CEE e Ásia/Pacífico) - sem, todavia, optar por associação com qualquer um deles -, ao aprofundamento da integração do Mercosul e à busca pela integração com o restante da América do Sul.

A vertente desenvolvimentista do período foi confirmada pela gestão do Chanceler Amorim, o qual assumiu a pasta das Relações Exteriores após a saída do Ministro Fernando Henrique Cardoso. A saída de Cardoso para assumir o Ministério da Fazenda abriu novo espaço ao corpo diplomático brasileiro no sentido de este voltar a gerir a definição dos rumos da política externa. Com efeito, o tema do desenvolvimento retornou com força ao discurso diplomático, tendo o Chanceler Amorim lançado mão, então, do que chamou de "diplomacia dos três Ds": desenvolvimento, desarmamento e democracia; em uma clara paráfrase ao modelo proposto, na década de 1960, pelo Ministro Araújo Castro, com sua também diplomacia dos três "Ds": desenvolvimento, desarmamento e direitos humanos.

Enquanto o Chanceler Cardoso concentrou esforços na implementação de reformas políticas e econômicas, na promoção do debate com a Academia e no diálogo com organizações empresariais e sindicais no que se refere ao processo de integração do Mercosul, o Ministro Amorim procurou, por sua vez, trazer à tona o conceito de "pragmatismo responsável", reflexo da chegada ao poder de geração de diplomatas que havia assistido o limite do projeto brasileiro de "potência emergente" ao final da década de 1970.

A atuação da política externa, durante o período, pode ser sintetizada, segundo o Chanceler Amorim ${ }^{11}$, pelos seguintes objetivos primordiais: a busca do desenvolvimento, a formação dos valores democráticos, a defesa da paz e da segurança internacionais e a luta em

\footnotetext{
11 AMORIM, Celso. "País precisa ter agenda externa própria". BRASIL/MRE. Resenha de política exterior do Brasil. Brasília: Departamento de comunicação e documentação do MRE, n. 74, $1^{\circ}$ semestre de 1994, p. 234.
} 
favor de ordem global econômica e politicamente mais justa. Nesse contexto, a América do Sul assumia a condição de prioridade da diplomacia. Por fim, a política externa do Governo Itamar teve como objetivo principal revalorizar a presença do Brasil no cenário internacional ao buscar refletir, no plano externo, os ideais compartilhados pela sociedade brasileira de consolidação da democracia e de busca do desenvolvimento com justiça social. Esteve inserida no contexto de recuperação econômica do País após a "década perdida" e de revigoramento do processo democrático doméstico, bem como de consolidação do processo de integração regional.

\section{O Governo Cardoso}

Com o fim do Governo Itamar, assumiu a Presidência da República o sociólogo e intelectual Fernando Henrique Cardoso, com a promessa de trazer reformas que conduziriam o País a novo patamar político, social e econômico. Com efeito, a gestão Cardoso logrou êxito inédito no campo econômico com o Plano Real, o qual obteve sucesso em acabar com a inflação de dois dígitos mensais, a custos não analisados no presente artigo. A política externa levada a cabo pelo Presidente Cardoso configura-se, sem dúvida, a mais estudada no período em tela.

A política externa do período esteve voltada para três elementos básicos: a defesa da democracia, a abertura ao exterior e a estabilidade econômica. Segundo o Presidente Cardoso ${ }^{12}$, "o resultado acumulado desses três processos de mudança é um País significativamente diferente daquele de há vinte ou trinta anos". Dessa forma, a diplomacia buscou consolidar a estabilidade econômica e a retomada do desenvolvimento de forma sustentável, por meio da abertura comercial e da atração de investimentos e tecnologias. Outras prioridades da política externa, durante o período, eram o Mercosul, o relacionamento com os vizinhos latino-americanos, as relações com o centro dos três pólos de poder econômico mundial (Estados Unidos, União Européia e Japão), as relações com os países continentais (China, Rússia e Índia), a implementação das diretrizes da Organização Mundial do Comércio, a reforma das Nações Unidas e a proteção de brasileiros no Exterior.

O Itamaraty buscou também dar prioridade a temas como integração, comércio, meio ambiente e direitos humanos. De acordo com o Chanceler Lampreia ${ }^{13}$, a política externa do Governo Cardoso buscou a "autonomia pela integração", isto é, uma autonomia articulada com o meio internacional, no sentido de que "não somos suficientemente atrelados a nenhum centro de poder mundial para justificar uma opção excludente". Assim, o Brasil deveria jogar em "tabuleiros não-excludentes", mantendo, destarte, todos os caminhos abertos, haja vista o potencial do País para perseguir presença ativa regional e internacional. ${ }^{14}$

No plano conceitual, pode-se dizer que, de acordo com o próprio Presidente Cardoso ${ }^{15}$, o Brasil estava disposto a desempenhar papel mais ativo na discussão de questões políticas

\footnotetext{
${ }^{12}$ LAMPREIA, Luiz Felipe. Diplomacia brasileira: palavras, contextos e razões. Rio de Janeiro: Ed. Lacerda, 1999, p. 10.

${ }^{13}$ LAMPREIA, Luiz Felipe. "A política externa do governo FHC: continuidade e renovação”. Revista Brasileira de Política Internacional. Brasília, v. 42, n. 2, p. 5-17, 1998, p. 11.

${ }^{14}$ LAMPREIA, Luiz Felipe. "O Brasil e o atual ordenamento político e econômico mundial". Cadernos do IPRI. Brasília: FUNAG, n. 7, junho de 1993, p. 31, 32.

${ }^{15}$ CARDOSO, Fernando Henrique. "A política externa do Brasil no Início de um novo século". Revista Brasileira de Política Internacional, Brasília, v. 44, n. 1, 2001, p. 10-11.
} 
internacionais. O Presidente acreditava haver um "déficit de governança" na política internacional, sendo que, para ele, a governança deveria ser construída sobre a legitimidade e a responsabilidade, as quais só se alcançariam por meio do diálogo e da participação. Além disso, ela deveria refletir, em sentido kantiano, um equilíbrio de poder entre as diferentes nações. Dessa forma, vencer desafios como pobreza, doença e exclusão social, mormente nos países em desenvolvimento, constituir-se-ia o verdadeiro desafio da governança no plano internacional. ${ }^{16}$

Para o historiador Amado Cervo ${ }^{17}$, a política externa do Presidente Cardoso dirigiu seus esforços em quatro rumos: multilateralismo, regionalismo, relações com os Estados Unidos e relações com a União Européia. Segundo o autor, a característica mais marcante do período foi o fato de o comércio exterior ter adquirido função de variável dependente da estabilidade de preços, perdendo, destarte, o caráter de instrumento estratégico de desenvolvimento e convivendo com a busca pelos fluxos de capital e a dependência financeira do País.

Para o Embaixador Seixas Corrêa ${ }^{18}$, por sua vez, o segundo Governo Cardoso buscou, no plano multilateral, "resgatar hipotecas" 19 que ainda pesavam sobre a nossa presença no mundo. Nesse sentido, a ratificação do Tratado de Não-Proliferação de Armas Nucleares (TNP) constituiu a iniciativa de maior relevância e visibilidade do período, concomitantemente com o fortalecimento e a expansão das relações com os Estados da América do Sul e a busca de "associações operacionais", como coloca o Embaixador ${ }^{20}$, com os países desenvolvidos, em particular, Estados Unidos e União Européia.

A característica mais marcante da política externa do Governo Cardoso, durante os dois mandatos, foi, sem dúvida, a execução da diplomacia presidencial - a qual envolveu uma sequiência de viagens cobrindo, praticamente, todas as regiões do mundo - como estratégia de ação da política externa de todo o período. Nas palavras do Chanceler Lampreia $^{21}$, o envolvimento direto do Presidente na diplomacia, devido à sua familiaridade e interesse com os temas internacionais, trouxe "a qualidade de sua liderança, reconhecida internacionalmente, que tem servido para ampliar a credibilidade política do País e respaldar a confiança em que (...) as diretrizes e compromissos adotados pelo governo irão concretizar-se".

Com efeito, a diplomacia presidencial disputou espaço com o Itamaraty no encaminhamento das questões de política externa. Para o Presidente Cardoso, o programa de viagens presidenciais era totalmente coerente com as prioridades da diplomacia. Segundo o Embaixador Sebastião do Rego Barros ${ }^{22}$, ex-Secretário-Geral do Itamaraty durante o período, as viagens e a diplomacia presidencial visavam a abranger e a cobrir "o universo das relações

\footnotetext{
${ }^{16}$ Há um artigo de Cardoso somente sobre a "governança progressiva para o século XXI" que explicita as opiniões do autor sobre a governança global. Ver CARDOSO, Fernando Henrique. "Governança progressiva para o século XXI”. Política Externa, v. 8, n. 3, dez/jan/fev de 2000.

${ }^{17}$ CERVO, Amado Luiz. "A política exterior: de Cardoso a Lula". Revista Brasileira de Política Internacional. Brasília, v. 46, n. 1, 2003, p. 5-8.

${ }^{18}$ CORREIA, Luiz Felipe de Seixas. "O Brasil e o mundo no limiar do novo século: diplomacia e desenvolvimento". Revista Brasileira de Política Internacional, Brasília, v. 42, n. 1, 1999, p. 6.

${ }^{19}$ A expressão utilizada entre aspas pertence ao ex-chanceler Luiz Felipe Lampreia. Cf. CORREIA, Luiz Felipe de Seixas. Idem, ibidem.

${ }^{20}$ Idem, p. 16-17.

${ }^{21}$ LAMPREIA, Luiz Felipe. “A política externa...”, op cit., p. 16.

22 BARROS, Sebastião do Rego. Política Externa em Tempo Real: a gestão do Embaixador Sebastião do Rego Barros no Itamaraty: discursos, artigos, palestras e relatórios. Brasília: FUNAG, 1999, p. 133.
} 
exteriores do Brasil na América do Sul, na América do Norte, na Europa e na Ásia, proximamente na África e no Oriente Médio". Para o Ministro Lampreia ${ }^{23}$, por sua vez, elas revelavam "um elemento de renovação e fortalecimento de nossa política externa".

De acordo com Sérgio Danese ${ }^{24}$, autor de livro sobre o assunto, a utilização da diplomacia presidencial durante o Governo Cardoso não tem precedentes na história diplomática brasileira. Tal fato deveu-se, como aponta o autor, à combinação inédita de dois elementos: a intensidade da agenda política externa do Presidente e a ênfase dada, no discurso diplomático, à diplomacia presidencial. Para o autor, "não apenas a diplomacia presidencial passou a ocupar grande parte do debate e da informação sobre a política externa, mas o próprio enfoque da política externa em geral passou a ser fortemente marcado pelo prisma da diplomacia presidencial". Com efeito, a diplomacia presidencial do Presidente Cardoso tornou-se, durante o período, o vetor de estratégia e ação da política externa brasileira.

\section{O Governo Lula}

Eleito sob a esperança de mudar o País, o Governo Lula representou o ápice do processo democrático no Brasil, fato consubstanciado na ascensão da esquerda ao poder em 2002. No plano diplomático, permitiu que o encaminhamento da política externa fosse conduzido por geração de diplomatas comprometida com o objetivo maior do desenvolvimento nacional e que se formou, no Instituto Rio Branco, sob os auspícios da "Política Externa Independente" de San Thiago Dantas - uma das fontes de inspiração do "Pragmatismo Responsável e Ecumênico" de Azeredo da Silveira.

Devido ao choque de desconfiança produzido pela ascensão de ex-líder sindicalista à Presidência da República e por anos de bravatas políticas do Partido dos Trabalhadores contrárias ao envolvimento do Brasil com instituições financeiras internacionais como, por exemplo, o Fundo Monetário Internacional, o Presidente Lula assumiu um País com grandes vulnerabilidades externas. Logo, desde o início do mandato, a superação dessas vulnerabilidades - deixadas sob responsabilidade do Ministério da Fazenda, do Ministério do Desenvolvimento, Indústria e Comércio Exterior (MDIC) e do Banco Central - constituíram um imperativo político para o novo Governo.

Nesse sentido, no que diz respeito ao plano econômico, pouca coisa foi alterada em relação à política empreendida durante o Governo Cardoso. Com efeito, a política monetária de juros altos para o controle da inflação, perseguida com afinco e miopia pela Banco Central, a meta de superávits primários, cumprida cegamente pelo Ministério da Fazenda e a busca por expressivo saldo positivo na balança comercial pelo MDIC remontam à gestão qualificada como "neoliberal" do ex-Presidente Cardoso.

A política externa do Governo Lula, por sua vez, tem buscado retomar o universalismo da diplomacia brasileira, princípio tão caro à tradição diplomática do País quanto a defesa irrestrita do multilateralismo nas relações internacionais. $\mathrm{O}$ caráter universal da gestão Lula faz lembrar a política externa dos Governos militares durante os anos setenta, quando "pragmatismo" e

\footnotetext{
${ }^{23}$ LAMPREIA, Luiz Felipe. “A política externa...”, op. cit., p. 16.

${ }^{24}$ DANESE, Sérgio. Op cit., p. 25.
} 
"universalismo" tornaram-se palavras de ordem durante o Governo Geisel. Nesse contexto, o Itamaraty tem buscado ampliar as relações com os parceiros estratégicos, formar novas coalizões frente às estruturas hegemônicas do sistema internacional e explorar nichos como a África e o Oriente Médio, os quais constituíram verdadeiros objetivos do universalismo da política externa na década de 1970, com o "Pragmatismo Responsável e Ecumênico" do Presidente Geisel.

O termo "pragmatismo", muito utilizado durante o Governo Geisel, servia para designar a política externa pragmática e "responsável dos Deveres da Nação", com atenção especial ao nosso relacionamento com as nações-irmãs da circunvizinhança de aquém e além-mar. A responsabilidade serviria para proteger o pragmatismo do epíteto de antiético. O ecumenismo, por sua vez, seria a ampliação de parcerias desejadas prescindidas de afinidades ideológicas e políticas em escala planetária. Da mesma forma, a busca por parceiros estratégicos, no atual Governo, não tem minado os esforços da diplomacia em privilegiar a América do Sul e as nações-irmãs da circunvizinhança na agenda diplomática, bem como em assegurar a continuidade de princípios universalistas da política externa como, por exemplo, pacifismo, autodeterminação e não-intervenção.

A atual política externa, além de buscar aliança, no contexto da cooperação Sul-Sul, com grandes países emergentes como China, Índia e Rússia, também insiste na consolidação do Mercosul como plataforma de propulsão para a concretização da recém-criada Comunidade SulAmericana de Nações, lançada por meio da Declaração Presidencial de Cusco, em 8 de dezembro de 2004. A essência da Comunidade Sul-Americana de Nações é o entendimento político e a integração econômica e social dos povos, tendo em vista o objetivo maior do desenvolvimento.

No campo do comércio internacional, o Governo Lula logrou alcançar novo patamar de negociações com a criação do G-20, durante a reunião ministerial de Cancun da Organização Mundial do Comércio, em 2003. O novo bloco, em sintonia com os interesses reais do Brasil e de outros países em desenvolvimento, busca a negociação em pé de igualdade com os países ricos na liberalização do comércio agrícola. No que se refere à integração hemisférica, a postura não tem sido distinta, tendo o Brasil defendido a posição única do Mercosul em negociações externas com outros blocos comerciais e em relação à futura Área de Livre Comércio das Américas. Com efeito, durante a IV Cúpula das Américas, realizada em Mar Del Plata, de 4 a 5 de novembro, o País defendeu a posição única do Mercosul de que não há condições propícias para seguir-se com as negociações da Alca no momento.

Por fim, não se pode deixar de mencionar os esforços empreendidos pelo atual Governo no campo social, o qual surgiu com vigor como novo e importante vetor da política externa. Para o Presidente Lula, não se pode discutir paz e segurança sem desenvolvimento econômico e justiça social. Diante desse contexto, o Presidente propôs a criação de um imposto sobre transações internacionais e sobre o comércio de armas para o financiamento de fundo mundial de combate à fome, angariando a simpatia de países como França, Chile e Espanha, além do apoio do Secretário-Geral das Nações Unidas, Kofi Annan. Dessa forma, o Brasil persegue política social condizente com as metas de desenvolvimento da Rodada do Milênio. A consecução do objetivo nacional de desenvolvimento com inclusão social reflete a melhor maneira de resumir os aspectos gerais da política externa do Governo Lula.

\section{Conclusão}


Ao longo das duas últimas décadas, o País teve quatro Presidentes que marcaram, cada um ao seu estilo, o encaminhamento da política externa. Se, por um lado, a diplomacia do Governo Collor buscou reintegrar o País aos fluxos dinâmicos da economia mundial, no intuito de promover a inserção competitiva do Brasil, a gestão Itamar, por outro lado, foi caracterizada pela adoção de posicionamento marcado pela condição do Brasil como país em desenvolvimento. A política externa do Governo Cardoso, por sua vez, esteve voltada para três elementos básicos: a defesa da democracia, a abertura ao exterior e a estabilidade econômica. Além disso, foi marcada pela execução da diplomacia presidencial como estratégia de ação da política externa.

Em relação ao Governo Lula, ainda que seja muito cedo para avaliar os desdobramentos de sua política externa, pode-se dizer que a diplomacia do período guarda traços comuns aos três Governos anteriores. Ou seja, tal como o Governo Collor - no qual o Chanceler Lafer buscou inserir o Brasil na discussão dos grandes temas da agenda internacional como, por exemplo, o meio ambiente -, a administração atual tem buscado manter alto nível de diálogo e intersecção entre as agendas interna e internacional. Em relação à gestão Itamar, basta mencionar a vertente desenvolvimentista comum aos dois Governos. Por fim, no que diz respeito à administração Cardoso, em termos de política externa, o Presidente Lula tem lançado mão da diplomacia presidencial em intensidade igual ou superior a seu antecessor.

É importante mencionar, à guisa de conclusão, que, independentemente do regime político interno, o Brasil sempre encaminhou a política externa como uma política de Estado, visà-vis a uma política de Governo. A política de Governo é aquela em que o interesse nacional é determinado pelo jogo político interno, variando de acordo com as percepções e as crenças dos atores nacionais. A política externa, por sua vez, é de Estado quando apresenta elementos de continuidade e persistência ao longo de um período superior a, no mínimo, o transcurso de dois Governos distintos. Reflete elementos materiais e simbólicos do Estado como população, território, nível de desenvolvimento, recursos naturais, tradição diplomática e nível de desenvolvimento tecnológico e científico. Isso contribui para política externa sólida, capaz de perpassar Governos de diferentes matizes políticas, uma vez que está comprometida com os interesses permanentes do Estado, os quais não estão sujeitos às vicissitudes do jogo político interno.

De modo a ilustrar questões de política externa nos últimos Governos que refletem o comprometimento da política externa com uma política de Estado têm-se: a busca do melhor relacionamento com países continentais como Índia, China e Rússia; a manutenção do relacionamento cordial com o principal parceiro diplomático, os Estados Unidos; a defesa da reforma das instituições das Nações Unidas; o comprometimento com os direitos humanos e com o meio ambiente saudável para as gerações futuras e a priorização do relacionamento com o entorno regional, mormente com os países do Mercosul. Por fim, o Itamaraty tem cuidado para que a política externa tenha alto grau de isolamento em relação aos fluxos do ambiente político e social, tornando-se, destarte, menos permeável às ingerências políticas. Todavia, o Ministério reconhece que o encaminhamento da política externa não deve ser feito de maneira unilateral e sim com o respaldo político interno, o qual difere de ingerência.

\section{Bibliografia}


BATISTA, Paulo Nogueira. “A política externa de Collor: modernização ou retrocesso?”. Política Externa, vol. 1, n. 4, março de 1999.

BARROS, Sebastião do Rego. Política Externa em Tempo Real: a gestão do Embaixador Sebastião do Rego Barros no Itamaraty: discursos, artigos, palestras e relatórios. Brasília: FUNAG, 1999, p. 133.

BRASIL/MRE. A inserção internacional do Brasil: a gestão do Ministro Celso Lafer no Itamaraty. Brasília, MRE, 1993.

Reflexões sobre a política externa brasileira. Brasília: FUNAG/IPRI, 1993 e BRASIL/MRE. A Política Externa do Governo Itamar Franco. Brasília: MRE, FUNAG, 1994.

Resenha de política exterior do Brasil. Brasília: Departamento de comunicação e documentação do MRE, $\mathrm{n}^{\circ}$. 74, $1^{\circ}$ semestre de 1994.

CARDOSO, Fernando Henrique. "A política externa do Brasil no Início de um novo século". Revista Brasileira de Política Internacional, Brasília, v. 44, n. 1, 2001.

2000.

. "Governança progressiva para o século XXI". Política Externa, v. 8, n. 3, dez/jan/fev de

CERVO, Amado Luiz. "A política exterior: de Cardoso a Lula". Revista Brasileira de Política Internacional. Brasília, v. 46, n. 1, 2003.

CORREIA, Luiz Felipe de Seixas. "O Brasil e o mundo no limiar do novo século: diplomacia e desenvolvimento”. Revista Brasileira de Política Internacional, Brasília, v. 42, n. 1, 1999.

DANESE, Sérgio. Diplomacia Presidencial. Rio de Janeiro: Topbooks Editora, 1999.

LAFER, Celso. "A inserção internacional do Brasil". O Estado de São Paulo. Caderno "Espaço Aberto", 23 de maio de 1992.

LAMPREIA, Luiz Felipe. "A política externa do governo FHC: continuidade e renovação". Revista Brasileira de Política Internacional. Brasília, v. 42, n. 2, p. 5-17, 1998.

. Diplomacia brasileira: palavras, contextos e razões. Rio de Janeiro: Ed. Lacerda, 1999.

. "O Brasil e o atual ordenamento político e econômico mundial". Cadernos do IPRI.

Brasília: FUNAG, n. 7, junho de 1993.

MÜLLER, June Beatriz. A politica externa brasileira nos governos Sarney, Collor e Itamar: um novo paradigma? Dissertação de Mestrado, Brasília: Universidade de Brasília, 2003. 